\title{
Desenvolvimento como Liberdade em uma Comunidade Ribeirinha da Amazônia: uma análise dos efeitos do Programa Bolsa Família em São Carlos, Porto Velho, Rondônia
}

\author{
Development as Freedom in a Amazon Riverside Community: an analysis of \\ the effects of Bolsa Família Program in São Carlos, Porto Velho, Rondônia
}

Pedro Abib Hecktheuer

Faculdade Católica de Rondônia, Porto Velho - RO, Brasil

Cássio Bruno Castro Souza

Faculdade Católica de Rondônia, Porto Velho - RO, Brasil

Fabio Rychecki Hecktheuer

Faculdade Católica de Rondônia, Porto Velho - RO, Brasil

Resumo: Neste artigo, discute-se se o Programa Bolsa Família (PBF) é uma política pública eficiente na expansão das liberdades substanciais dos indivíduos. Para responder ao problema proposto, a pesquisa realizou uma pesquisa de campo no Distrito de São Carlos, localizado no Município de Porto Velho, Rondônia. Os achados demonstram que o Programa Bolsa Família é uma alternativa bem-sucedida, já que proporciona aos ribeirinhos melhores condições de vida. $\mathrm{O}$ acesso a utilidades básicas, como alimento, materiais escolares e vestuário, é garantido pelo programa, tendo em vista que uma grande parcela de pessoas dessas comunidades, embora desenvolvam atividades laborativas voltadas à subsistência, não possui vínculo formal e renda fixa.

Palavras-chave: Desenvolvimento e Liberdade. Programa Bolsa Família. Comunidade Ribeirinha.

Recebido em: 30/08/2017

Revisado em: 15/03/2018

Aprovado em: 05/04/2018
Abstract: In this paper, it was reflected whether the Bolsa Família Program is an efficient public policy in the expansion of the substantial freedoms of individuals. To answer the proposed problem, the research conducted a field research in the District of São Carlos, located in Porto Velho, Rondônia. The research shows that the Bolsa Família is an successful alternative by providing better living conditions for the river communities. The access to basic utilities, such as food, school materials and clothing, are guaranteed by the program. This is extremely important, since, in these places, families do not have a fixed income, and not by disinterest in employment, but by the fact that, even if they develop occupational activities focused on subsistence, they do not have any formal employment relationship.

Keywords: Development and Freedom. Bolsa Família Program. Riverside Community. 


\section{Introdução}

A Constituição da República 1988 firmou um compromisso com o desenvolvimento. Não são poucas as passagens na Constituição em que o desenvolvimento é escolhido como um objetivo a ser perseguido pelo Estado brasileiro na formulação de suas políticas públicas. Para a Constituição de 1988, o desenvolvimento não está reduzido a um mero sinônimo de opulência econômica. Muito embora o crescimento econômico (aferido pelo produto interno bruto) seja um elemento importante para avaliar o nível de bem-estar de uma determinada população, o desenvolvimento a ele não se reduz. O processo de desenvolvimento deve, sobretudo, viabilizar a todos uma existência digna, reduzir as desigualdades sociais e regionais e eliminar a pobreza.

Sem prejuízo das inúmeras concepções e aspirações de desenvolvimento presentes na Constituição, é sobre essa perspectiva que esse artigo avaliará a eficiência das políticas públicas desenhadas pelo Estado brasileiro: a partir de sua capacidade em reduzir desigualdades sociais e regionais e eliminar a pobreza.

A política pública eleita é o Programa Bolsa Família, criado pela Lei n. 10.836, de 9 de janeiro de 2004, com o propósito de promover a transferência direta de renda a pessoas/unidades familiares em situação de extrema pobreza. O Governo Federal rompeu com o propósito constituinte de universalização de políticas sociais (observado pelo programa que antecedeu o Programa Bolsa Família: o programa Fome Zero) e atribuiu à nova política pública um contestado perfil focalizante (SOARES, 1995).

O problema que esta pesquisa pretende responder é se o Programa Bolsa Família (PBF) é uma política pública eficiente na expansão das liberdades substanciais dos indivíduos, com ênfase na população ribeirinha da comunidade amazônica de São Carlos, em Porto Velho, Rondônia?

O PBF, ao focalizar o gasto social e promover uma transferência de renda direta para os indivíduos, contribui para a expansão de suas liberdades substanciais, seja pelo aumento da renda, seja pelos efeitos causados pelas condicionantes do programa (aumento das oportunidades sociais ao 
melhorar a frequência e o aproveitamento de crianças e adolescentes na escola), seja por evitar a morte prematura e a desnutrição de crianças pobres.

A hipótese trabalhada neste artigo afirma que o PBF é uma política pública eficiente na expansão das liberdades substanciais dos indivíduos da comunidade ribeirinha de São Carlos. Para responder ao problema proposto realizou-se: (1) ampla revisão bibliográfica de pesquisas dedicadas a verificar os impactos socioeconômicos do PBF em outras regiões do país, bem como de dados oferecidos pelo IBGE e IPEA e; (2) pesquisa de campo, por meio de entrevistas e questionários, no Distrito de São Carlos, localizado no Município de Porto Velho, Rondônia.

A escolha desse local é justificada pela particularidade do modo de vida de seus habitantes: ribeirinhos, cuja inserção na economia de mercado ocorre de modo particular, como bem se irá abordar. Além disso, verificar a eficácia da política pública sobre comunidades tradicionais é inédito. A perspectiva da liberdade trabalhada na noção de desenvolvimento de Amartya Sen é, neste artigo, testada em uma comunidade de pessoas com um modo de vida peculiar e com uma visão de boa vida também particular.

A primeira parte da pesquisa será dedicado a explicar que o desenvolvimento é um processo contínuo de expansão de liberdades substanciais. Trabalhar-se-á a perspectiva de desenvolvimento forjada por Amartya Sen e se verificará como o Programa Bolsa Família, na forma como desenhado, contribui para o processo de desenvolvimento brasileiro.

Na segunda parte, cuidar-se-á de apresentar ao leitor a comunidade de São Carlos e explicar por qual razão ela foi eleita para a pesquisa de campo. Também se descreverá a metodologia adotada na pesquisa empírica e, por fim, se apresentará os resultados observados pelos pesquisadores.

\section{Desenvolvimento para Além do Aspecto Econômico: o modelo jurídico de desenvolvimento}

Como antecipado, a ideia de desenvolvimento, para a Constituição da República Federativa do Brasil (CRFB) de 1988, não está reduzida a 
uma preocupação com a opulência econômica experimentada por determinada população. Desenvolvimento, portanto, não é expressão sinônima de crescimento econômico e existe uma diferença básica entre crescimento e desenvolvimento. Enquanto o conceito de crescimento compreende todas as maneiras de progresso econômico: transformações estruturais, incremento a longo prazo da população e do produto per capita, representando, então, um processo quantitativo (RISTER, 2007, p. 1-2), o conceito de desenvolvimento compreende dinâmicas mutações e um processo de mobilidade social de caráter contínuo e intermitente. Como se pode perceber, os objetivos do desenvolvimento superam o mero crescimento econômico e estão relacionados às "[...] implicações da reforma jurídica para um espectro mais amplo de resultados sociais, entre eles, o respeito aos direitos humanos, a igualdade de gênero e, de modo mais geral, a justiça distributiva" (DAVIS; TREBILCOCK, 2009, p. 221).

Enquanto que o crescimento é aferido pela medição do PIB, o desenvolvimento pode ser verificado a partir de diversos indicadores, como o Índice de Desenvolvimento Humano (IDH) e o Índice de Desenvolvimento Humano Ajustado à Desigualdade (IDHAD), que são adotados pelo Programa das Nações Unidas para o Desenvolvimento, e o coeficiente GINI.

A ideia de desenvolvimento não é nova e a expressão começou a ser utilizada já no final da Segunda Guerra Mundial, junto com as expressões "[...] subdesenvolvimento, países em via de desenvolvimento e países atrasados [...]”, para se referir a países não industrializados (RISTER, 2007, p. 13), revelando já o seu conteúdo ideológico e comparativo (FOLLONI, 2014, p. 67). Ou seja, o nível de desenvolvimento de determinado país seria sempre relativo e comparado a países que já teriam atingido um nível ótimo de desenvolvimento. Por essa razão, os valores e instituições presentes em países que atingiram um grau ótimo de desenvolvimento deveriam ser reproduzidos nos países subdesenvolvidos. O subdesenvolvimento traduziria justamente o estado das sociedades cujas economias não conseguiram (ainda) alcançar o estágio de crescimento autossustentado (RISTER, 2007, p. 21) e identificar quais são os sistemas de valores e de estruturas vigentes que mais viabilizam o desen- 
volvimento de uma determinada sociedade num dado momento histórico é o desafio proposto desde meados do século XX.

$\mathrm{O}$ enfrentamento desse desafio de moldar instituições que facilitem o processo de desenvolvimento depende, entretanto, da tentativa de construção de um modelo jurídico do desenvolvimento possa contribuir para o reequacionamento desse processo (RISTER, 2007, p. 38). Daí se falar em um direito dos povos ao desenvolvimento.

A CRFB de 1988 escolheu um modelo de desenvolvimento que, ao mesmo tempo em que não se limita à mera opulência econômica, pretende garantir a todos os indivíduos uma existência digna, reduzir as desigualdades sociais e regionais e eliminar a pobreza. O modelo jurídico de desenvolvimento da CRFB de 1988 pode ser identificado como um modelo de ampliação de liberdades substanciais por considerar o desenvolvimento como um direito fundamental assegurado por prestações positivas devidas pelo Estado.

A CRFB aprofundou o tratamento jurídico do desenvolvimento (FOLLONI, 2014, p. 70-71). Já no seu preâmbulo, afirma instituir um Estado encarregado de assegurar a todos o desenvolvimento. A garantia do desenvolvimento nacional é um dos objetivos da República Federativa do Brasil (BRASIL, 1988, art. $3^{\circ}$ ). Em outros diversos momentos, a Constituição trata do desenvolvimento, sob os mais diversos aspectos ${ }^{1}$.

Como se pode observar, a CRFB de 1988 não adota um modelo de desenvolvimento baseado unicamente no crescimento econômico. $\mathrm{O}$ modelo constitucional de desenvolvimento pretende "[...] uma elevação no padrão de vida de toda a sociedade, não só padrão financeiro ou econômico. Por isso, o desenvolvimento é das pessoas e da sociedade que as

1 A Constituição fala em um desenvolvimento nacional, um desenvolvimento tecnológico (inciso XXIX do art. $5^{\circ}$ ), um desenvolvimento econômico (art. 239, § $1^{\circ}$ ), um desenvolvimento social, um desenvolvimento econômico e social (inciso IX do art. 21), um desenvolvimento regional, um desenvolvimento equilibrado $\left(\S 1^{\circ}\right.$ do art. 174 e art. 192), um desenvolvimento urbano (inciso XX do art. 21 e art. 182), um desenvolvimento científico e tecnológico (art. 200, V, art. 218 e art. 219, 219-A e 219-B), um desenvolvimento do ensino (art. 212), um desenvolvimento cultural ( $\$ 3^{\circ}$ do art. 215), um desenvolvimento humano, social e econômico (art. 216-A) (BRASIL, 1988). 
formam e que elas formam, ao lado das questões restritivamente econômicas." (FOLLONI, 2014, p. 80)

Essa constatação é importante para esta pesquisa. O modelo de desenvolvimento acolhido pela Constituição Federal tem por propósito viabilizar eliminação da pobreza e a marginalização e redução das desigualdades sociais e regionais. E esse propósito, que deve ser alcançado a partir do processo de desenvolvimento, pressupõe a formulação de políticas públicas que expandam as liberdades substanciais dos indivíduos.

\subsection{O Desenvolvimento como um Processo Contínuo de Expansão de Liberdades Substanciais}

O economista indiano Amartya Sen busca demonstrar que o desenvolvimento pode ser visto como a expansão de liberdades que os sujeitos gozam. Em síntese, o desenvolvimento requer que se removam as principais fontes de privação da liberdade, como a "[...] pobreza, tirania, carência de oportunidades econômicas e destituição social sistemática, negligência dos serviços públicos e intolerância ou interferência excessiva de Estados repressivos" (SEN, 2000, p. 18).

Para Sem (2000), as liberdades são relevantes para o processo de desenvolvimento, por duas razões: a) a avaliatória, segundo a qual o progresso deve ser analisado sob o prisma de aumento das liberdades das pessoas; e b) a da eficácia, que estabelece a interdependência entre o desenvolvimento e a livre condição do indivíduo.

Como se demonstrará ao longo deste artigo, o programa analisado pressupõe a transferência condicionada de dinheiro a pessoas pobres. E, nesse sentido, é relativamente fácil entender a relação entre o Programa Bolsa Família e a proposta de desenvolvimento de Sen, uma vez que a utilidade da riqueza reside nas liberdades subjetivas que ela ajuda a obter, de maneira que o desenvolvimento deve estar atrelado à melhoria de vida, de modo a possibilitar maior completude dos indivíduos como seres humanos. Por essa razão, a análise centrada nas liberdades não está metodologicamente limitada à avaliação de bem-estar, uma vez que a abordagem de Sen vai além do utilitarismo, porque sua preocupação está voltada para o modo que as pessoas vivem e não somente com a quantidade de ren- 
da auferida. Exatamente por objetivar a expansão de liberdades reais dos indivíduos, o desenvolvimento é um processo amigável. Essa percepção se distancia, portanto, da ideia de que o desenvolvimento é um processo indesejável ou inviável (FOLLONI, 2014, p. 70).

A importância da liberdade para o processo de desenvolvimento é explicada em duas razões: as liberdades individuais substantivas são consideradas essenciais e a liberdade é um determinante principal da iniciativa individual e da eficácia social. Essa expansão pode ser vista como o fim primordial ou papel constitutivo e o principal meio do desenvolvimento ou o papel instrumental da liberdade no desenvolvimento.

O primeiro relaciona-se com a importância da liberdade substantiva no enriquecimento da vida humana, pois essas liberdades incluem a capacidade de evitar privações como a fome, a subnutrição, a morbidez e a morte prematura, bem como a participação política e a liberdade de expressão. A seu tempo, do papel instrumental das liberdades, infere-se que elas também contribuem de forma eficaz para o progresso econômico, já que o papel instrumental das liberdades está relacionado ao modo como os tipos de direitos ou oportunidades contribuem para a expansão da liberdade humana e, por conseguinte, para a promoção do desenvolvimento.

Este trabalho analisará como as facilidades econômicas e as oportunidades sociais contribuem para o processo de desenvolvimento para, mais tarde, avaliar a eficácia do Programa Bolsa Família. As facilidades econômicas cuidam de oportunidades de que dispõem os indivíduos para utilizar produtos com o objetivo de consumo, produção ou troca. Dependem dos recursos disponíveis, das condições de troca, dos preços relativos e o funcionamento dos mercados. Oportunidades sociais, a seu tempo, tratam do acesso à educação, saúde e demais elementos que possibilitem que o indivíduo viva melhor e, consequentemente, participe de forma mais efetiva na economia e na política. 


\section{Programas de Transferência de Renda como Políticas Efica- zes de Expansão de Liberdades Substanciais: Universalização, Focalização e Eficiência do Gasto Social}

O Programa Bolsa Família (doravante PBF) surge em 2003, como uma política pública de transferência de renda condicionada. O programa tem como destino unidades familiares que se encontram em situação de extrema pobreza (BRASIL, 2004, inciso I do art. $2^{\circ}$ ). Com base nos dados revelados pela Pesquisa Nacional por Amostragem de Domicílios (PNAD) de 1999 , estimava-se que $27,8 \%$ da população brasileira estaria situada abaixo da linha da pobreza (MONTEIRO, 2003).

Em síntese, o PBF surge como uma estratégia de focalização de programas sociais. Na contramão do desejo constituinte de 1988 (que sempre foi o de universalizar programas sociais, como o sistema único de saúde, o sistema único de assistência social e a previdência social), a política pública desenhada a partir de 2003 objetivou focalizar o gasto público nos mais pobres.

Como explica Thomé (2013, p. 77), “[...] a focalização é feita combinando métodos estatísticos geográficos e de renda per capita. O Ministério de Desenvolvimento Social determina, pelos registros, as famílias que serão beneficiadas, as quais estão inscritas no Cadastro Único". Esse aparente rompimento com o desejo constituinte ao abandonar a política de universalização de serviços destinados à superação da pobreza extrema é o que torna a análise do Programa Bolsa Família mais interessante a partir da perspectiva do desenvolvimento como liberdade.

A transferência direta de renda, nos moldes do PBF, contribui para o desenvolvimento como processo contínuo de expansão de liberdades a partir de duas perspectivas. Em primeiro lugar, ao atribuir ao indivíduo a escolha a respeito de como gastar a renda transferida, o programa contribui para o acréscimo de suas capacidades.

O indivíduo, e não o Estado, empregaria a renda transferida para adquirir os bens de consumo que desejasse, levando a vida que tem razão para valorizar. Evidentemente, o beneficiário possui razões suficientes 
para empregar os recursos na aquisição de bens materiais necessários à sua subsistência (tendo em vista, sobretudo, o valor reduzido dos valores transferidos). Em suma, o programa privilegia a descentralização das decisões tomadas no mercado no lugar do planejamento central.

Em segundo lugar, as condicionantes do programa contribuem para que os beneficiários gozem de oportunidades sociais (saúde e educação básicas). Sobre esse efeito do PBF na aquisição de oportunidades sociais se falará no próximo capítulo.

\subsection{O Condicionamento de Transferência de Renda como Elemento de Expansão de Oportunidades Sociais e Econômicas}

O PBF exerce um importante papel na redução da pobreza e da desigualdade e a dependência política. Além disso, produz importantes efeitos sobre o consumo e a produção (NERI et al., 2013, p. 193). Esses efeitos macroeconômicos causados pelo aumento de renda já foram descritos por Sen. O aumento de renda é importante porque viabiliza o exercício de outras liberdades, como o investimento em capital humano (melhorias em saúde e educação), o acesso a postos de trabalho com melhores remunerações e condições e trabalho, o consumo de bens e serviços que garantam uma situação de bem-estar.

Mas o Programa Bolsa Família não é um programa de transferência de renda incondicionada. O recebimento do benefício do Programa Bolsa Família depende do cumprimento de condicionalidades relativas ao exame pré-natal, ao acompanhamento nutricional, ao acompanhamento de saúde, à frequência escolar de $85 \%$ (oitenta e cinco por cento) em estabelecimento de ensino regular, sem prejuízo de outras previstas em regulamento (BRASIL, 2004, art. $3^{\circ}$ ).

Esses condicionamentos são importantes por garantir às famílias pobres (e, sobretudo, às crianças que integram essas famílias) oportunidades sociais relacionadas à educação básica e à saúde preventiva. Ao incentivar a preocupação com a educação e saúde preventiva (expandido as oportunidades sociais), o programa promove a formação de capital humano, ampliando as facilidades econômicas para ingresso no mercado de trabalho e participação nas trocas econômicas. 
Glewwe e Kassouf (2008) observaram que o PBF influenciou nas taxas de matrícula, abandono escolar e progressão escolar. Os pesquisadores estimam que o Programa Bolsa Família, entre 1998 e 2005, aumentou as taxas de matrícula em $5,5 \%$ das crianças da $1^{\mathrm{a}}$ à $4^{\mathrm{a}}$ série e $6,5 \%$, no caso das crianças da $5^{\mathrm{a}}$ à $8^{\mathrm{a}}$ série. $\mathrm{O} \mathrm{PBF}$ ainda teria contribuído para a redução das taxas de abandono escolar em $0,5 \%$ (para crianças da $1^{\mathrm{a}}$ a $4^{\mathrm{o}}$ série) e $0,4 \%$ (para as crianças da $5^{\mathrm{a}}$ à $8^{\mathrm{a}}$ série). Houve acréscimo, ainda, nas taxas de aprovação em cerca de $0,9 \%$ (da $1^{\mathrm{a}}$ à $4^{\mathrm{a}}$ série) e $0,3 \%$ (da $5^{\mathrm{a}}$ à $8^{\mathrm{a}}$ série). Entretanto, apenas $1 / 3$ das crianças brasileiras estavam, à época da pesquisa, inseridas no programa (GLEWWE; e KASSOUF, 2008). Desse modo, seria razoável supor que o impacto do programa seja três vezes maior que o estimado. Isso fará com que, a longo prazo, a taxa de matrícula dentre os participantes do programa, alcance $18 \%$. A redução do abandono alcançaria $1,5 \%$ e a taxa de progressão escolar $2 \%$.

Os números parecem dizer muito sobre a eficácia do programa na formação de capital humano. Entretanto, se é correto dizer que o efeito esperado a longo prazo seja um acréscimo de $18 \%$ nas taxas de matrículas de crianças participantes do programa, significa que $82 \%$ dos beneficiários do programa já estariam matriculados na escola independentemente do PBF (2008). Essa conclusão sugere que a transferência de renda seria benéfica apenas pelo objetivo distributivo (de aumento de renda).

Débora Thomé reconhece que, em alguns casos na América Latina, programas de transferência de renda semelhantes ao PBF foram importantes no aumento da frequência escolar, da escolaridade ou da taxa de matrícula. (THOMÉ, 2013, p. 80). Não foi o que aconteceu no Brasil, contudo. O PBF não teve um impacto tão relevante na taxa de matrícula (que já era alta entre as crianças e jovens de 7 a 14 anos) e não existem evidências fortes de que o PBF tenha impactado de modo relevante o acompanhamento pré-natal e o estado nutricional de crianças (THOMÉ, 2013, p. 80). Débora Thomé argumenta que até 2006 o PBF foi responsável por uma queda de mais de 19\% no índice GINI (THOMÉ, 2013, p. 81).

A pesquisa empírica revelada neste trabalho foi realizada em São Carlos, Distrito de Porto Velho. Quando se observa o Relatório Brasil Sem Miséria do Município de Porto Velho (gerado em 27 de maio de 
2016), percebe-se que $92,70 \%$ das crianças e jovens de 6 a 17 anos inseridas no Programa Bolsa Família têm acompanhamento de frequência escolar. A frequência supera a média nacional, que é de $86,70 \%$.

$\mathrm{Na}$ área da saúde, o acompanhamento é menor e não alcança 35\% (chega a 34,92 \% das famílias com perfil, ou seja, aquelas com crianças de até 7 anos e/ou com gestantes). Nesse ponto, Porto Velho está abaixo da média nacional, que é de 76,81\%. Esses números são semelhantes aos do Município de Joinville, em que o acompanhamento de frequência escolar de crianças e jovens de 6 a 17 anos chega a 91,63\% e, na área da saúde, 35,50\% (SCHIMDT, 2016, p. 110).

Percebe-se que, se por um lado a frequência escolar de crianças e jovens beneficiados pelo PBF é alta, o acompanhamento na área da saúde não é satisfatório. Esse desempenho não satisfatório pode ser explicado pelo grau de cobertura da rede de saúde e pela deficiência de fiscalização das condicionantes, pelo Poder Público. No caso do Programa Bolsa Família, os custos de monitoramento do agente são altos e os incentivos criados com o propósito de alinhar interesses não são adequados, seja porque a cobertura da rede de acompanhamento em saúde preventiva é baixa, seja porque os incentivos à realização do pré-natal não são suficientes.

\section{A Peculiar Inserção das Comunidades Ribeirinhas Amazôni- cas no Capitalismo e a Necessária Complementação da Renda}

O povoamento da Amazônia por não indígenas não é algo recente, processo que se iniciou em meados do século XVII, mas foi mesmo a partir do século XVIII, inicialmente, com os missionários da Coroa Portuguesa por meio da catequese e, posteriormente, com os ciclos da borracha que se passou a haver uma maior integração do homem não indígena com a floresta amazônica brasileira, com ênfase na bacia do Rio madeira que é o objeto desta pesquisa (SERRA, 2001, p. 19).

$\mathrm{O}$ que surgia, no final do século XIX e início do século XX, era uma grande oportunidade em função do alto valor que o mercado internacional vinha atribuindo à borracha, ou seja, “[...] o surgimento do ciclo 
da borracha transformou-se em grande polo de atração para as populações rurais do Nordeste." (NASCIMENTO SILVA, 2000, p. 48).

Esse processo perdurou até o desenvolvimento da extração de látex na Ásia, fazendo com que houvesse um declínio significativo da extração da borracha na região amazônica, resultando na dissolução dos seringais e, via de consequência, o povoamento nas matas e margens dos rios da Amazônia, com o desenvolvimento de uma nova forma de viver, "[...] o espaço ribeirinho assume características que o diferenciam, por exemplo, do espaço rural, o que pode ser explicado [...]" (SARAIVA; SILVA, 2001, p. 8) pela miscigenação entre índio e nordestino, que deu a origem ao caboclo amazônico ${ }^{2}$ (SERRA, 2001, p. 21).

O modo de produção do homem ribeirinho foi modificado com o esgotamento do clico econômico da borracha, que o levou a se fixar na terra para constituir moradia e desenvolver atividades comerciais com outros moradores, bem como desenvolver mecanismos que os mantivessem naquela terra (SERRA, 2001, p. 21).

Esse processo é que deu origem a diversos povoamentos isolados, que se organizaram e criaram modos de vida diferenciados nos mais diversos aspectos, como cultural, alimentar, de organização para o trabalho, etc. (SERRA, 2001, p. 21). Há comunidades ribeirinhas que são essencialmente extrativistas e outras que desenvolvem uma agricultura centrada na produção familiar (ASSEF MENDES et al., 2008, p. 4).

Os ribeirinhos desenvolveram uma dinâmica bastante diferenciada na sua relação com a terra e o meio ambiente, é uma cultura que possibilitou a resistência com o passar dos anos, marcado por simplicidade e solidariedade, herdado dos indígenas, o que fica evidenciado nas características físicas, alimentação e na moradia, que, normalmente, são construídas de palafitas à beira dos rios (SARAIVA; SILVA, 2001, p. 8-10). O fato é que o caboclo usufrui da natureza de forma sustentável, sem promover queimadas ou destruições, esse povo conserva o meio ambiente de onde tira sua alimentação e sustento familiar.

\footnotetext{
${ }^{2} \mathrm{O}$ caboclo é aquele que nasceu e assimilou a cultura das terras Amazônicas, incluindose também o "índio amansado", que é aquele que perdeu os seus traços característicos adquirindo um modo de vida igual ao de sua nova convivência (SERRA, 2001, p. 19).
} 
As comunidades serem às margens dos rios significa um importante dado a ser levado em conta no presente estudo, uma vez que os ribeirinhos ficam isolados da cidade em função dos elevados custos de transporte, não tendo acesso às mídias escrita e internet, apenas às mídias televisiva e radiofônica (ASSEF MENDES et al., 2008, p. 4). É um povo que sofre poucas interferências, portanto, mantendo uma vida à margem do imediatismo e da pressa típica dos grandes centros urbanos (SERRA, 2001, p. 21).

Afora todas as peculiaridades inerentes às comunidades tradicionais que carecem de estudos e de reconhecimento, para nossa pesquisa, importante se faz que se avalie as peculiaridades do seu estilo de trabalho.

Trata-se de um povo que, como relatado, utiliza os espaços e o tempo para as suas necessidades cotidianas e momentâneas em um ritmo próprio, não havendo o desejo de acumulação. Via de consequência, não se encontra nessas comunidades as características encontradas nas cidades, de urgência com horários, jornadas de trabalho, plantão, etc. Na grande parte, não são proprietários de terras, mas lá habitam e assentam residência, podendo ampliar ou restringir área de cultivo ou de criação de animais, às florestas e rios estão à sua disposição. Importante que se conheçam essa peculiaridades para não se rotular essas comunidades como muito se fez com os povos indígenas ao caracterizá-los como "preguiçosos, sem ânimo ou inertes" (SERRA, 2001, p. 21; MENEZES, 2016, p. 12).

$\mathrm{O}$ que se verifica nessas comunidades, em função das peculiaridades supracitadas, é que possuem uma relação não capitalista de produção mediadora, pelas dificuldades de acesso ao mercado, fazendo com que o agricultor dessas regiões produza apenas para sua subsistência e o excedente é apenas trocado por alimentos em alguma mercearia, isso se a situação não é ainda pior em que o ribeirinho já está endividado e a pouca produção já comprometida, inclusive a de sua subsistência.

Há uma significativa distinção entre a forma de trabalho dessas comunidades com relação à dos meios urbanos, que é o fato de o produto do seu trabalho não ser compreendido como mercadoria, pois a sua finalidade é o sustento da família ou do grupo, e a venda do pequeno excedente se dá para aquisições de mercadorias que não são oriundos desses grupos. 
Pode-se dizer que, ainda que estejam inseridos no processo mercadológico próprio do capital, não extraem a mais-valia e não possuem a lógica do lucro (SILVA, 2007, p. 44).

Somado a isso, é de se ressaltar que o trabalho destas comunidades tem como outra peculiaridade que a distingue das outras sociedades o fato de que a mão de obra utilizada no processo produtivo é a familiar (SILVA, 2007, p. 44).

Pela pouca quantidade, a produção atual ainda não insere o ribeirinho no mercado, mas o capitalismo tem prevalecido sobre a cultura e especificidades dos diversos povos e comunidades tradicionais, dentre eles as ribeirinhas. Ao mesmo tempo, identifica-se que a relação com a natureza é o bem mais precioso destas pessoas, o que se mantém vivo, assim como é notória a necessidade de melhores condições de vida, o que se contrasta com as possíveis consequências negativas com relação à cultura, as crenças e mitos, próprios desse povo que o capitalismo acelerado pode gerar (SERRA, 2001, p. 27).

É nesse contexto que se buscam alternativas que possam contribuir com o desenvolvimento dessa população, de forma que se estabeleçam novos modos de produção e de sistemática de trabalho para ingressar no mercado sem que se percam as características e a cultura dessas populações.

\section{O Programa Bolsa Família como meio para a Expansão das Liberdades dos Moradores da Comunidade de São Carlos}

A pesquisa de campo se desenvolveu na comunidade ribeirinha de São Carlos, município de Porto Velho, Estado de Rondônia. Deve-se salientar que a delimitação aconteceu em função de já serem diversas as pesquisas desenvolvidas em municípios subdesenvolvidos das diversas regiões brasileiras, ainda que nem todas com o mesmo foco (ROCHA, 2011; ALVES; MESQUITA, 2014; ANSELL, 2014; BRAGA et al., 2015; LIMA et al., 2014; SCHMIDT, 2016), no entanto, não há relatos de estudos econômico-jurídicos do PBF em uma comunidade ribeirinha, o que demonstra a originalidade e relevância social do estudo 
Ainda que se haja feito uma contextualização geral sobre as origens das comunidades ribeirinhas e suas peculiaridades, importante se faz a apresentação dos dados referente à comunidade de São Carlos.

\subsection{As Origens de São Carlos}

A comunidade fruto da pesquisa desenvolvida fica localizada na área rural do município de Porto Velho, capital do estado de Rondônia, à beira do Rio Madeira, principal afluente do Amazonas. $\mathrm{O}$ acesso pode se dar de duas maneiras, por via fluvial desde Porto Velho, ou desde a outra margem do rio, nas proximidades da comunidade, após um longo trecho de estrada de chão batido, ambos ficam cerca de 120 quilômetros à jusante do município de Porto Velho e cerca de 200 quilômetros à montante da divisa de Rondônia com o estado do Amazonas (NAPRA, 2015).

As origens dos moradores de São Carlos assim como os da região são as mesmas da grande maioria das demais comunidades ribeirinhas da bacia amazônica, tendo suas origens no povoamento de trabalhadores de seringais que existiam na sua proximidade, que se deu após a partida dos patrões (seringalistas), em meados do século XX (LABADESSA, 2012, p. 55; NAPRA, 2015).

Atualmente São Carlos é uma das maiores comunidades do Baixo Madeira com, aproximadamente, 370 famílias e cerca de 1.300 habitantes. Deve-se salientar que a pesquisa foi desenvolvida na comunidade ribeirinha de São Carlos e não em todas as comunidades do Distrito de São Carlos, que alberga outras 11 comunidades $^{3}$ (CAETANO; SILVA; ALVES, 2017, p. 351-353; NAPRA, 2015).

Outro fator de extrema importância e que impacta as considerações de nossa pesquisa é a existência de três geradores comunitários instalados, que abastecem, atualmente, 98\% das habitações com energia, mantido por empresas concessionárias, sendo que os geradores são movidos a diesel, gerando alto nível de ruído e de poluentes, sem se falar o alto custo da energia para as famílias (NAPRA, 2015).

\footnotetext{
${ }^{3}$ Tais como Brasileira, Boca do Jamari, Terra Caída, Cavalcante, Curicacas; Bom Será, Sobral, RESEX Lago do Cuniã, Itacoã, Primor, Jamari, etc.
} 
As principais atividades da comunidade são a pesca, agricultura, extrativismo (castanha e açaí), uma parcela de comerciantes (mercearia, bar, farmácia, pousada, revenda de produtos locais), além de possuir uma significativa parcela de servidores públicos (10\% da população), sempre com relatos de que faltam oportunidades de trabalho na comunidade, indo ao encontro do já trazido pela bibliografia a esse mesmo respeito (NAPRA, 2015).

\subsection{Metodologia Desenvolvida}

A pesquisa tinha como metodologia principal para alcançar o objetivo geral a realização de entrevistas semiestruturadas com os beneficiários do Programa Bolsa Família, para o fim de obter o contato direto com o fenômeno estudado, por meio da obtenção de dados primários, em consonância com a metodologia de pesquisas já realizadas sobre o mesmo fenômeno (SCHMIDT, 2016).

A pesquisa desenvolvida, quanto à abordagem, foi qualitativa e quantitativa, com uma interação constante entre as duas abordagens, como forma de proporcionar a complementariedade para a superação de possíveis falhas. Não se pode deixar de salientar que o contato direto do pesquisador com seus sujeitos de pesquisa é uma maneira de proporcionar a interpretação das linguagens corporais e inflexões verbais do sujeito investigado, além de possibilitar a coleta de dados diretamente, o que poderia ser prejudicado em um questionário escrito em função da baixa escolaridade, já que por muito tempo, na comunidade, só havia até o quarto ano do ensino médio, fato que impossibilitou a maior parte dos beneficiários concluir o ensino básico.

Deve-se salientar que há uma grande incongruência entre a quantidade de famílias beneficiárias do PBF nas diferentes comunidades do Distrito de São Carlos. Nem mesmo os responsáveis pela checagem de saúde realizada semestralmente tinham certeza de quantas famílias beneficiárias eram de São Carlos ou das demais localidades da região, tam- 
pouco havia registro correto nas listagens sobre o local da moradia de muitas famílias ${ }^{4}$.

Optou-se por entrevistar a totalidade dos beneficiários encontrados nas listagens obtidas, por se tratar de uma quantidade não muito elevada de famílias, e por não ser a comunidade territorialmente muito grande, tendo sido possível realizar as pesquisas em quatro dias de entrevistas em períodos diversos, durante o segundo semestre do ano de 2017.

Foram inseridos na entrevista alguns eixos de perguntas, como perguntas relacionadas à qualificação e dados gerais do entrevistado; questões relacionadas ao trabalho, possibilidades de emprego, se há interesse do beneficiário em estar empregado, etc; na sequência o foco foi aferir o grau de conhecimento sobre as condicionantes do PBF, e a importância do PBF para a saúde e escolaridade dos filhos; buscou-se, ainda, compreender a importância do PBF para a família e onde os recursos são empregados; e, por fim, partiu-se para uma parte livre e aberta, que consistiu em abrir um espaço para o entrevistado poder opinar, sem qualquer estímulo inicial, sobre o Programa Bolsa Família.

Depois de obter o posicionamento favorável à realização da pesquisa $^{5}$, e após obter junto ao posto de saúde da comunidade de São Car-

\footnotetext{
${ }^{4}$ A falta de certeza da quantidade de famílias beneficiárias do PBF, especificamente de São Carlos, se deve a dois fatores: (a) a comunidade de São Carlos foi afetada por uma cheia histórica do Rio Madeira, no ano de 2014, tendo sido necessário que o Estado retirasse todas as famílias da comunidade durante a cheia que devastou a comunidade. Depois de voltar à normalidade, muitas famílias tiveram suas residências destruídas, tendo como consequência o abandono da comunidade, por parte de muitas famílias, fenômeno que ainda vem acontecendo, o que tem gerado uma flutuação populacional muito grande, tornando difícil a aferição precisa de quais são as famílias beneficiárias do PBF nestas comunidades atingidas pela cheia e; (b) em função da peculiaridade da organização das comunidades ribeirinhas que fazem com que não haja previsão do endereço preciso das famílias, apenas a localidade.

${ }^{5}$ Para iniciar a pesquisa exploratória de coleta de dados, requereu-se autorização junto ao Serviço de Assistência Social do município de Porto Velho, que indicou o contato junto aos agentes de saúde e de educação da Comunidade de São Carlos, lugar onde se pode ter acesso aos cadastrados ativos e que cumpriram as condicionantes do programa na última triagem. Tudo em consonância com o Decreto n. 6.135, de 2007 e na Portaria n. 10, de 2012 do Ministério do Desenvolvimento Social.
} 
los uma tabela com dados dos beneficiários do Programa Bolsa Família, como: titular; data de nascimento; endereço; bairro; número de dependentes; nomes dos dependentes, partiu-se para as entrevistas.

Ao se delimitarem apenas àquelas moradoras da comunidade de São Carlos, encontrou-se 25 famílias beneficiárias, das quais apenas 22 puderam ser entrevistadas ${ }^{6}$, já que as demais não foram encontradas, em suas residências nos quatro dias de pesquisa.

Dessa forma, foi necessário auxílio de agentes de saúde e lideranças para o fim de encontrar a residência dos titulares beneficiários, não tendo havido nenhum contato anterior com os entrevistados. É importante ressaltar que nenhum beneficiário se negou a ser entrevistado, e apenas três famílias não foram encontradas, dentre as 25 que eram objeto do estudo.

\subsection{Resultados Obtidos}

Foram, portanto, realizadas 22 entrevistas, com duração média de 30 minutos cada uma, sendo que todas foram realizadas com mulheres, e a administração dos recursos é feita, na maior parte dos casos, em conjunto com o marido. Esse dado vai ao encontro da lei que prevê que o pagamento do benefício será, preferencialmente, feito à mulher (BRASIL, 2004), sendo que na pesquisa realizada, a realidade era de um maior número de mulheres entre 31 e 40 anos de idade (50\%), seguido pela faixa de 41 a 60 anos (36\%), por fim, as mais jovens, entre 18 a 30 anos, representaram apenas $14 \%$ da população analisada.

Outra questão que torna ainda mais peculiar a situação das famílias ribeirinhas é o fato de que a maioria delas não se via em condições de apresentar uma renda total média familiar, pois não há renda fixa na grande parte das famílias, sendo que muitas vivem apenas do valor do Programa Bolsa Família, e em outros casos a renda é extremamente variável a depender do sucesso com a pesca e venda do pescado naquele período.

\footnotetext{
${ }^{6}$ Resta deixar claro que não havia maiores detalhes com relação ao endereço e ao telefone das famílias, muito provavelmente em função das peculiaridades dessas comunidades, por não haver linha de telefone e tampouco sinal de celular, bem como por terem formas diferenciadas de organização.
} 
Como já relatado, essas comunidades são caracterizadas pela subsistência e solidariedade, seja por meio da pesca, extrativismo ou agricultura, tinham saciado todas as suas necessidades sem se fazer necessário uma renda (dinheiro) quando ainda não havia necessidades como, por exemplo, energia elétrica e consequentemente a obrigação de pagamento de conta, quando ainda não havia o fogão e consequentemente necessidade de aquisição de gás, quando inexistiam escolas e consequentemente não era necessária a aquisição de materiais escolares.

No momento em que todas essas necessidades foram criadas, bem como não apenas essas, mas todas as demais que foram artificialmente inseridas, característico do capitalismo, principalmente por meio da televisão, trouxeram consigo a obrigação de as famílias buscarem maneiras de compor essa renda mínima necessária para arcar com as despesas. O fato é que essas famílias possuem modos de vida que impossibilitam, em determinados aspectos, que se possam saciar essas necessidades acima arroladas.

Ainda que $95 \%$ dos entrevistados digam não ter emprego, deve-se compreender como emprego formal e nos moldes daquele emprego do meio urbano (Tabela 1), pois são em realidade, na sua maioria, pescadores, extrativistas e agricultores, mas de subsistência, e apenas quando há excedente, e quando é possível, se comercializa, ou seja, em realidade possuem atividades, mas um trabalho que não lhes possibilita a renda necessária.

Outro ponto bastante importante e que foi relatado por grande parte das beneficiárias que possuem filhos adolescentes é o fato de que gostariam que os filhos estivessem empregados e que, no entanto, na comunidade não há essa possibilidade (NAPRA, 2015), isso justifica inclusive que $77 \%$ das entrevistadas (Tabela 1 ) entenda que procurar emprego não deva ser condicionante para o recebimento do benefício do PBF.

Além disso, a negação da busca/procura de emprego como condicionante do BPF se deve ao fato de que as beneficiárias, como acima relatado, já possuem afazeres diários (agricultura de subsistência, extrativismo ou pesca) e funções que as impossibilitaria de ter qualquer outro tipo de emprego, sem esquecer que os afazeres domésticos na comunidade e o cuidado com os filhos são função da mulher. 
Tabela 1: Grupo de perguntas relacionadas ao emprego da pesquisa sobre a redistribuição de renda na comunidade ribeirinha de São Carlos, Porto Velho, Rondônia

\begin{tabular}{ccc}
\hline Questionamentos & Sim & Não \\
\hline Está empregado? & $1(5 \%)$ & $21(95 \%)$ \\
Procurar emprego/estar empregado deveria ser uma condicionante para & $5(23 \%)$ & $17(77 \%)$ \\
\hline
\end{tabular}

Fonte: Elaborada pelos autores deste artigo

O programa tem o condão de estimular o consumo e a economia nacional, sendo utilizado na aquisição de alimentos, material escolar, medicamentos e vestuário. Ainda que o consumo das comunidades ribeirinhas possa não ter representatividade sobre a economia nacional, os relatos não divergiram do que se vem encontrando em outras pesquisas sobre o PBF, tendo sido encontrado na presente pesquisa que a maior parte dos recursos do BPF são destinados à alimentação e materiais escolares $(30 \%)$, vindo logo abaixo os gastos com vestuário (27\%).

Os dados encontrados em nossa pesquisa se coadunam com os dados encontrados por Weissheimer (2006, p. 94) em que "os recursos recebidos por meio do programa foram gastos em primeiro lugar, em larga maioria, com alimentação $(76,4 \%)$ [...] e "uma outra parcela das famílias $(11,1 \%)$ priorizou a compra de material escolar", bem como em trabalhos recentes como o de Schmidt (2016, p. 73), no qual a alimentação vem, também, em primeiro lugar na destinação dos recursos do PBF, seguido por vestuário, remédios e material escolar (Gráfico 1).

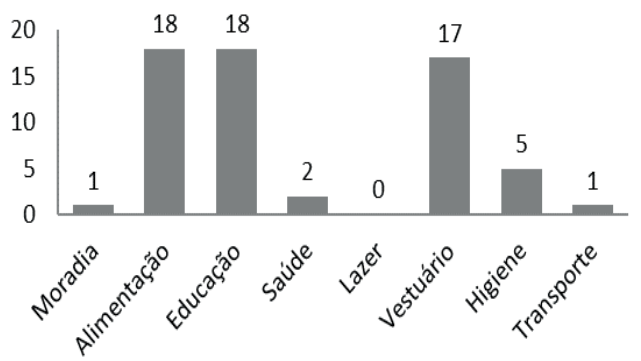

Gráfico 1: Relação de itens básicos com os quais os beneficiários usam os recursos recebidos pelo Programa Bolsa Família na comunidade ribeirinha de São Carlos, Porto Velho, Rondônia

Fonte: Elaborado pelos autores deste artigo 
Pode-se salientar que na comunidade de São Carlos o uso do BPF se dá para arcar, principalmente, os gastos com alimentação, o que confirma a alta importância que as beneficiárias dão ao BPF para a alimentação da família (Gráfico 2), com educação (compra de materiais escolares) e com vestuário.

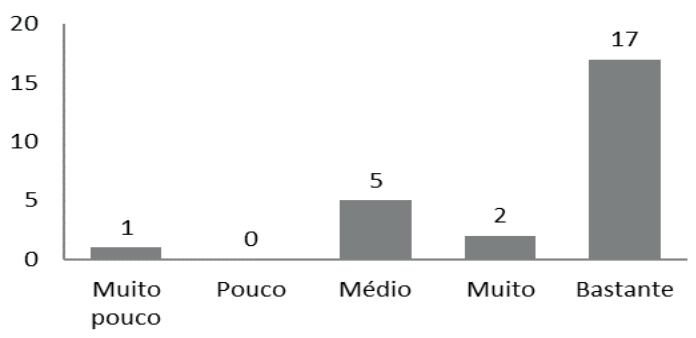

Gráfico 2: Avaliação por parte dos beneficiários com relação à importância do Programa Bolsa Família para a alimentação de sua família, na comunidade ribeirinha de São Carlos, Porto Velho, Rondônia

Fonte: Elaborado pelos autores deste artigo

É interessante ressaltar que, apesar de a alimentação dos ribeirinhos ser predominantemente oriunda da pesca há diversas outras carências alimentares que não são saciadas e carecem de serem compradas nas mercearias, sem esquecer que para o próprio preparo do alimento se exige o uso do gás (fogão), óleo (fritura) entre outros condimentos (arroz, etc.). Daí justificada a grande importância do BPF para a alimentação destas famílias.

De maneira semelhante, evidenciou-se em outra pesquisa que os recursos do PBF tiveram um bom impacto sobre o consumo de alimento pelas famílias beneficiárias, tendo sido encontrado uma elevação considerável do consumo, repercutindo direta e positivamente na questão da insegurança alimentar (BAPTISTELLA, 2015).

O PBF é um programa que exige o cumprimento de algumas condicionantes para o recebimento do benefício, fazendo com que seja necessária uma rede de circulação de informações por meio das escolas e postos de saúde. Os gestores municipais de educação encaminham os nomes das crianças oriundas de famílias beneficiadas pelo PBF às escolas para 0 controle de frequência, dados que são repassados mensalmente ao muni- 
cípio para a verificação do cumprimento. Esses dados de cumprimento da condicionante são acompanhados pelo ministério da educação e de Desenvolvimento Social para aferição da política pública (SCHMIDT, 2016; WEISSHEIMER, 2006).

Da mesma forma acontece com a saúde, com a diferença de que as aferições ocorrem semestralmente, a começar com os dados colhidos nos postos de saúde, tendo seu término no Ministério da Saúde (SCHMIDT, 2016, p. 52), ou seja, “[...] o acompanhamento das contrapartidas de saúde é coordenado pelo Ministério da Saúde e feito pelas secretarias municipais de saúde." (SOARES; SÁTYRO, 2009, p. 16).

As condicionantes são de conhecimento de todas as entrevistadas e são adequadamente cumpridas por todas as beneficiárias, que consideram, na sua maioria $(86 \%)$, de fácil cumprimento (Tabela 2), bem como também na mesma porcentagem consideram que essas condicionantes não devem ser excluídas do PBF.

Tabela 2: Questionário realizado para o desenvolvimento da pesquisa sobre a redistribuição de renda na comunidade ribeirinha de São Carlos, Porto Velho, Rondônia

\begin{tabular}{ccc}
\hline Questionamentos & Sim & Não \\
Você conhecesse as condicionantes do programa? & $22(100 \%)$ & $0(0 \%)$ \\
São difíceis de cumprir? & $3(14 \%)$ & $19(86 \%)$ \\
Se você pudesse excluir as condicionantes, o faria? & $3(14 \%)$ & $19(86 \%)$ \\
\hline
\end{tabular}

Fonte: Elaborada pelos autores deste artigo

Os resultados iniciais com relação às condicionantes do programa foram expressivos (WEISSHEIMER, 2006, p. 57) e os números vinham mostrando um avanço no setor educacional em que "a porcentagem de frequência escolar [...] que era de $51 \%$ em outubro e novembro de 2004 , subiu para $61 \%$ nos três primeiros meses de 2005 ", não se confirmando o otimismo em outros estudos que põe dúvidas sobre as condicionalidades por que "[...] não se sabe ao certo quão necessárias são as condicionalidades [...]" e "[...] quanto se gasta para controlá-las e o que exatamente se ganha com isso.” (MEDEIROS; BRITTO; SOARES, 2007, p. 14). 


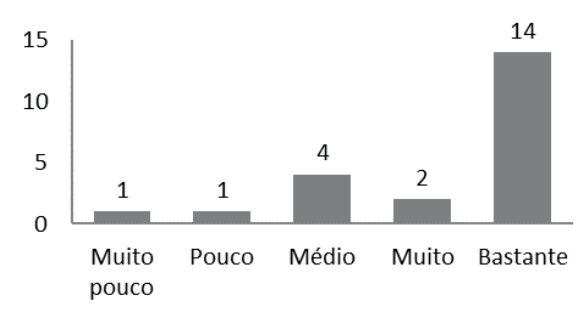

Gráfico 4: Avaliação por parte dos beneficiários com relação à importância do Programa Bolsa Família para a permanência dos filhos na escola, na comunidade ribeirinha de São Carlos, Porto Velho, Rondônia

Fonte: Elaborada pelos autores deste artigo

A percepção das beneficiárias de São Carlos vai ao encontro do que os autores relatam no sentido de considerar que os condicionantes do PBF são extremamente importantes, principalmente para a manutenção dos filhos de beneficiários da comunidade na escola (Gráfico 4).

Por outro lado, diversas pesquisas empíricas demonstram que o programa impactou positivamente no setor educacional (FREIRE et al., 2013; SOARES; RIBAS; OSÓRIO, 2010; CACCIAMALI; TATEI; BATISTA, 2010; DUARTE; SILVEIRA NETO, 2008), apresentando aumento da frequência escolar (WEISSHEIMER, 2006, p. 57-102) e redução do abandono escolar dos estudantes beneficiários em relação aos dos estudantes não beneficiários no ensino fundamental e médio (FREIRE et al., 2013, p. 161).

Os dados empíricos da pesquisa desenvolvida demonstram que na realidade ribeirinha analisada o PBF tem sido uma alternativa extremamente bem-sucedida para proporcionar às famílias melhores condições, principalmente dos acessos básicos, como alimento, materiais escolares e vestuário, em uma realidade em que famílias não possuem renda fixa.

Bem como, os dados estão em consonância com a grande maioria das pesquisas já desenvolvidas para avaliar esta política, nos mais diversos contextos. Por fim, deve-se ressaltar que as pesquisas sobre o PBF na realidade ribeirinha são precárias e, portanto, carece-se de outros estudos para que se possa compreender melhor a influência desta política no contexto ribeirinho amazônico. 


\section{Conclusão}

As políticas de transferência de renda têm se demonstrado uma importante ferramenta de proteção social, tendo o Brasil dado visibilidade pelo tão grande alcance de seu programa (PBF). Como fora discutido, são diversas as pesquisas que objetivam compreender, perceber e avaliar essa política do governo federal, no entanto, um ponto em comum destas iniciativas tem sido a busca de dados empíricos para fundamentação dos resultados, o que se reproduziu, também, no presente estudo.

Ressalta-se que grande parte das pesquisas sobre o PBF tem se dedicado ao estudo do programa em centros urbanos, nos quais a dinâmica e as formas de trabalho e de vida são semelhantes, guardadas às peculiaridades regionais. A possibilidade de ter como objeto de estudo o Programa Bolsa Família em uma comunidade ribeirinha proporcionou uma abordagem inédita e resultados relevantes, que não se podem entender como um produto acabado, ou uma realidade unívoca sobre o programa nessas comunidades, mas um recorte dentre outros diversos possíveis, que não está isento de falhas e equívocos e que tampouco podem levar a uma generalização, mas sim como um achado que deve ser levado em conta.

Para se compreender o Programa Bolsa Família e as peculiaridades da comunidade ribeirinha de São Carlos, foi necessário buscar embasamentos teóricos para compreender as origens e os modos de vida e de trabalho das comunidades ribeirinhas. Verificou-se a figura do índio na origem dessas comunidades, dos quais se absorveram diversas características, tanto na relação com o meio ambiente e ao modo de vida.

É um traço o desenvolvimento de atividades como pesca, extrativismo e agricultura de subsistência, sem a existência de excedentes significativos para o fim de extração de mais-valia. O lucro não é uma característica desses povos, que buscam saciar as suas necessidades diárias e cotidianas, sem acúmulo de bens. Possuem, portanto, um modo particular de inserção na economia de mercado.

Posteriormente, passou-se a analisar a comunidade de São Carlos e suas peculiaridades, partindo para análise da pesquisa empírica desenvolvida com 22 famílias beneficiárias do Programa Bolsa Família, que 
proporcionou compreender que PBF tem sido uma ferramenta bastante importante nessa realidade.

Constatou-se que na totalidade das entrevistas o beneficiário era mulher, que relataram a grande importância que o programa tem para a alimentação de suas famílias, principalmente nos períodos em que a pesca diminui pela cheia do Rio Madeira, bem como para a compra de itens necessários para a alimentação (gás, óleo, arroz, etc.), bem como para arcar com custos de aquisição de itens oriundos de fora da comunidade, como materiais escolares e vestuário, vez que a maior parte dessas famílias não possui renda fixa, mesmo desenvolvendo atividades (pesca, extrativismo, etc.).

Um dado importante é o fato de todos os beneficiários conhecerem as condicionantes do PBF, relatarem o fiel cumprimento desses benefícios e mencionarem como isso é importante para a permanência dos filhos na escola.

A hipótese pode ser confirmada e o problema respondido vez que o $\mathrm{PBF}$, na realidade ribeirinha, demonstrou-se uma alternativa extremamente bem-sucedida para proporcionar aos ribeirinhos melhores condições, principalmente dos acessos básicos, como alimento, materiais escolares e vestuário, em uma realidade em que famílias não possuem renda fixa, e não pelo desinteresse pelo emprego, pois ele inexiste, mas pelo fato de que, ainda que desenvolvam atividades laborativas (pesca, extrativismo, agricultura) voltadas à subsistência, sem condições de acessar os longínquos mercados dos centros urbanos para a venda dos, nem sempre existentes, excedentes de produção.

\section{Referências}

ALVES, Ivanilda Souza; MESQUITA, Shirley Pereira de. O Programa

Bolsa Família: uma análise de seus limites e potencialidades enquanto política pública intersetorial, transversal e focalizada. 2014. $21 \mathrm{p}$. Monografia (Trabalho de Conclusão de Curso da Pós-graduação lato sensu) - Departamento de Economia, Centro de Ciências Sociais Aplicadas, Universidade Federal da Paraíba, João Pessoa, 2014. Disponível em: $<\mathrm{http}: / /$ biblioteca.virtual.ufpb.br/files/o_programa_bolsa 
famalia_uma_analise_de_seus_limites_e_potencialidades_enquanto polatica_pablica_intersetorial_transversal_e_focalizada_1343840722. pdf $>$. Acessado em: 3 jul. 2018.

ANSELL, Aaron. Zero Hunger: political culture and antipoverty policy in northeast Brazil. The University of North Carolina Press: Chapel Hill, 2014.

ASSEF MENDES, Leila Said et al. Inserção ecológica no contexto de uma comunidade ribeirinha amazônica. Interamerican Journal of Psychology, [S.l.], v. 42, n. 1, p. 1-10, 2008.

BAPTISTELLA, Juliana Carolina Frigo. Avaliação de programas sociais: uma análise do impacto do bolsa família sobre o consumo de alimentos e status nutricional das famílias. 2012. Disponível em: $<$ http://www.orcamentofederal.gov.br/educacao-orcamentaria/premiosof-de-monografias/v-premio/1_Lugar_Juliana_Carolina.pdf $>$. Acesso em: 5 ago. 2015.

BRAGA, Maria Goretti Serpa; DINIZ, Leandro Charles; JUNIOR, Stelio Gama Lyra. Microcredito como ação complementar ao Programa Bolsa Família; a experiência do Crediamigo do BNB. Universidade Federal do Ceara/Banco do Nordente do Brasil, 2008.

BRASIL. Lei n. 10.836, de 9 de janeiro de 2004. Cria o Programa Bolsa Família e dá outras providências. Diário Oficial [da] República Federativa do Brasil, Poder Legislativo, Brasília, DF, 9 jan. 2004. Disponível em: <http:/www.planalto.gov.br/ccivil_03/_ato20042006/2004/lei/110.836.htm>. Acesso em: 7 jul. 2015.

CACCIAMALI, M. C.; TATEI, F.; BATISTA N. F. Impactos do programa bolsa família federal sobre o trabalho infantil e a frequência escolar. Revista de Economia Contemporânea, [S.l.], v. 14, p. 269-301, 2010. CAETANO, Renato Fernandes; SILVA, Raimundo Nonato Pereira; ALVES, Eva da Silva. O território como elemento constituidor da identidade sociocultural dos povos e comunidades tradicionais: a constituição sócio histórica da comunidade ribeirinha de São Carlos. Revista Saberes da Amazônia, [S.l.], v. 2, n. 5, p. 348-363, 2017. 
DAVIS, Kevin E.; TREBILCOCK, Michael J. A relação entre direito e desenvolvimento: otimistas versus céticos. Tradução de Pedro Maia Soares. Revisão Técnica de José Rodrigo Rodriguez. Revista de Direito GV, São Paulo, jan.-jun. p. 217-268, 2009.

FOLLONI, André. A complexidade ideológica, jurídica e política do desenvolvimento sustentável e a necessidade de compreensão interdisciplinar do problema. Revista Direitos Humanos Fundamentais, Osasco, ano 14, n. 1, p. 63-91, jan.-jun. 2014.

GLEWWE, P.; KASSOUF, A. L. The Impact of the Bolsa Escola/ Familia Conditional Cash Transfer Program on Enrollment, Drop Out Rates and Grade Promotion in Brazil. Department of Applied Economics, University of Minnesota, 2008.

LABADESSA, Aparecido Silvério. "Terras Caídas”, as causas naturais e antrópicas: uma ocorrência na comunidade de São Carlos - Médio Madeira/RO. Geoingá: Revista do Programa de Pós-Graduação em Geografia, [S.l.], v. 3, n. 1, p. 45-61, 2012.

MEDEIROS Marcelo; BRITTO Tatiana; SOARES, Fábio Veras. Transferência de renda no Brasil. Revista Novos Estudos, [S.l.], n. 79, p. 5-29, nov. 2007. Disponível em: <http://www.scielo.br/pdf/nec/n79/01. pdf>. Acesso em: 2 jul. 2017.

MENEZES, Elisangela Ferreira. "Sou da beira do Madeira": Interfaces entre Juventude e Gênero na área ribeirinha de Porto Velho-RO.

Simpósio Linguagens e Identidades da/na Amazônia Sul-Ocidental, Rio Branco/AC, n. 1, 2016. SIMPÓSIO LINGUAGENS E IDENTIDADES DA/NA AMAZÔNIA SUL-OCIDENTAIS. Anais..., Rio Branco/SC, n.1, 2016. Disponível em: <http://revistas.ufac.br/revista/index.php/ simposioufac/search/titles? searchPage=8>. Acessado em: 2 jul. 2018. MONTEIRO, Carlos Augusto. A dimensão da pobreza, da desnutrição e da fome no Brasil. São Paulo. 2003. Disponível em: $<$ http://www.scielo.br/scielo.php?script=sci_arttext\&pid=S0103$40142003000200002 \& \operatorname{lng}=\mathrm{en} \& \mathrm{nrm}=\mathrm{iso}>$. Acesso em: $1^{\mathrm{o}}$ ago. 2017. 
NAPRA, Núcleo de Apoio à População Ribeirinha da Amazônia. São Carlos do Jamari. 2015. Disponível em: <http://www.napra.org.br/ comunidades-apoiadas/sao-carlos-do-jamari/> Acesso em: 2 jul. 2017.

NASCIMENTO SILVA. Maria das Graças Silva. O Espaço Ribeirinho. São Paulo: Terceira Margem. 2000.

NERI, Marcelo Côrtes; VAZ, Fabio Monteiro; SOUZA, Pedro Herculano Guimarães Ferreira de. Efeitos macroeconômicos do programa bolsa família: uma análise comparativa das transferências sociais. In: CAMPELLO, Tereza. NERI, Marcelo Côrtes. Programa Bolsa Família: uma década de inclusão e cidadania. Brasília: Ipea, 2013. p. 193206. Disponível em: $<\mathrm{http}: /$ www.ipea.gov.br/agencia/images/stories/ PDFs/131015_bolsa_familia_cap11.pdf $>$, Acesso em: 8 set. 2017.

RISTER, Carla Abrantkoski. Direito ao desenvolvimento: antecedentes, significados e consequências. São Paulo: Renovar, 2007.

ROCHA, Sônia. O programa Bolsa Família: evolução e efeitos sobre a pobreza. Revista Economia e Sociedade, Campinas, v. 20, n.1 (41), p. 113-139, abr. 2011.

SARAIVA, Adriano Lopes; SILVA, José da Costa. A (re) organização do espaço na vila de Nazaré: a criação do bairro de São Sebastião. Revista de Educação, Cultura e Meio Ambiente, [S.l.], v. IV, n. 3, p. 5-14, 2001.

SCHMIDT, Albano Francisco; GONÇALVES, Oksandro Osdival. O Programa Bolsa Família e a acomodação de seus beneficiários na cidade de Joinville - SC: uma análise econômica dos (des) incentivos ao trabalho. 2016. 225 p. Dissertação (Mestrado) Pontifícia Universidade Católica do Paraná, Curitiba, 2016. Disponível em: $<$ http://www.biblioteca.pucpr.br/pergamum/biblioteca/img. php?arquivo=/00005c $/ 00005 \mathrm{cfb} . p d f>$. Acesso em: 6 fev. 2017.

SEN, Amartya Kumar. Desenvolvimento como liberdade. Tradução de Laura Teixeira Motta. São Paulo: Companhia das Letras, 2000.

SERRA, Nara Eliana Miller. Compreendendo a Lógica do Trabalho em Populações Tradicionais Ribeirinhas Populações Tradicionais 
Ribeirinhas. Revista de Educação, Cultura e Meio Ambiente, [S.l.], v. IV, n. 3, p. 18-27, 2001.

SILVA, Elane Cristina Lima da. A dinâmica das relações comunitárias na Amazônia: estudo de caso das formas de ajuda mútua praticadas na comunidade ribeirinha de Tauarú no município de Tabatinga-AM. 2007. 154 f. Dissertação (Mestrado em Sociedade e Cultura na Amazônia) Universidade Federal do Amazonas, Manaus, 2007.

SOARES, Fábio Veras; RIBAS, Rafael Perez; OSÓRIO, Rafael Guerreiro. Evaluating the impact of Brazil's Bolsa Familia: Cash transfer programs in comparative perspective. Latin American Research Review, [S.l.], v. 45, n. 2, p. 173-190, 2010.

SOARES, Laura Tavares Ribeiro. Ajuste Neoliberal e Desajuste Social na América Latina. Tese (Doutorado) - Unicamp. Campinas: São Paulo, 1995.

SOARES, Sergei; SÁTYRO, Natália. O Programa Bolsa Família: desenho institucional, impactos e possibilidades futuras. Instituto de Pesquisa Econômia Aplicada. Brasília: Governo Federal, 2009. Disponível em: <http:/www.ipea.gov.br/portal/images/stories/PDFs/TDs/ td_1424.pdf $>$. Acessado em: 2 jul. 2017.

SUPLICY, Eduardo Matarazzo; BUARQUE, Cristovam. Garantia de renda mínima para erradicar a pobreza: o debate e a experiência brasileiros. Revista Estudos Avançados, São Paulo, v. 11. n. 30, maio/ ago. 1997. Disponível em: <http://www.scielo.br/scielo.php?script=sci_ar ttext\&pid $=$ S0103-40141997000200007> . Acesso : $1^{\circ}$ ago. 2017.

THOMÉ, Débora. O Bolsa Família e a social-democracia. Rio de Janeiro: Editora FGV, 2013.

WEISSHEIMER, Marco Aurélio. Bolsa Família: avanços, limites e possibilidades do Programa que está transformando a vida de milhões de famílias no Brasil. São Paulo: Perseu Abramo, 2006. 
Pedro Abib Hecktheuer é professor de Direito Constitucional da Faculdade Católica de Rondônia, Coordenador do Curso de Direito da Faculdade Católica de Rondônia (FCR). Graduado em Direito pela Faculdade Palotina de Santa Maria, Rio Grande do Sul (FAPAS). Mestrando em Direito Econômico e Socioambiental pela Pontifícia Universidade Católica do Paraná (PUCPR). Bolsista junto à Fundação Rondônia de Amparo ao Desenvolvimento das Ações científicas e tecnológicas e à Pesquisa do Estado de Rondônia - FAPERO/CAPES.

E-mail:pedro@fcr.edu.br.

Endereço profissional: Rua Gonçalves Dias, 290, Centro, Porto Velho, Rondônia. CEP: 76801-132.

Cássio Bruno Castro Souza é professor de Direito do Trabalho e Processo do Trabalho da Faculdade Católica de Rondônia (FCR). Graduado em Direito pela Universidade Federal de Rondônia (UNIR). Mestrando em Direito Econômico e Socioambiental pela Pontifícia Universidade Católica do Paraná (PUCPR).

E-mail: cassio.souza@fcr.edu.br.

Endereço profissional: Endereço: Rua Gonçalves Dias, 290, Centro, Porto Velho, Rondônia. CEP: 76801-132.

Fabio Rychecki Hecktheuer é professor dos Cursos de Direito e Filosofia e Diretor Geral da Faculdade Católica de Rondônia (FCR). Professor do Programa de Pós-graduação em Ciência Política da Universidade Federal do Rio Grande do Sul (UFRGS). Graduado em Filosofia pela Universidade Católica de Pelotas (UCPEL). Mestre em Filosofia pela Pontifícia Universidade Católica do Rio Grande do Sul (PUCRS). Doutor em Desarrollo Psicológico y Aprendizaje Escolar pela Universidad Autonoma de Madrid (UAM). Pós-doutorado em Psicologia da Aprendizagem pela Universidad Autonoma de Madrid (UAM).

E-mail: fabioheck@fcr.edu.br.

Endereço profissional: Rua Gonçalves Dias, 290, Centro, Porto Velho, Rondônia. CEP: 76801-132. 